\title{
Preclinical investigations of a medium-chain triglyceride:fish oil emulsion III. Experiments in cultured endothelial cells
}

\author{
YVON A. CARPENTIER, ISABELLE DUPONT, LAURENCE PORTOIS and WILLY J. MALAISSE \\ Laboratory of Experimental Surgery, Brussels Free University, B-1070 Brussels, Belgium
}

Received April 10, 2006; Accepted July 28, 2006

\begin{abstract}
The bolus intravenous injection of a novel mediumchain triglyceride:fish oil emulsion was recently reported to provoke a rapid and sustained increase in the cell phospholipid content of long-chain polyunsaturated $\omega 3$ fatty acids in both rats and human subjects. This report deals mainly with a comparison between this and other emulsions, as well as albumin-bound $\omega 3$ fatty acids, in terms of the time course, reversibility and concentration dependency for the incorporation of the $\omega 3$ fatty acids in the phospholipids of cultured endothelial cells. The results document that the new emulsion is quite efficient for a rapid and sustained enrichment of phospholipids in long-chain polyunsaturated $\omega 3$ fatty acids. The potential beneficial effects of such an enrichment in terms of aortic endothelial and cardiac function are emphasized.
\end{abstract}

\section{Introduction}

The bolus intravenous injection of a medium-chain triglyceride:fish oil (8:2, w:w) emulsion (MCT:FO) to normal subjects was recently reported to provoke within $60 \mathrm{~min}$ and for at least 24-48 h a sizeable increase in the phospholipid content of long-chain polyunsaturated $\omega 3$ fatty acids in platelets and white blood cells (1). This procedure was considered, therefore, as a possible tool to rapidly restore, in selected subjects, a sufficient concentration of these $\omega 3$ fatty acids in cell phospholipids in order, for instance, to protect such subjects against the risk of cardiac arrhythmia following anesthesia and surgery.

The present study, part of which was already reported in abstract form $(2,3)$ refers mainly to the time course and

Correspondence to: Professor Willy J. Malaisse, Laboratory of Experimental Hormonology, Brussels Free University, 808 Route de Lennik, B-1070 Brussels, Belgium

E-mail: malaisse@ulb.ac.be

Key words: long-chain polyunsaturated $\omega 3$ fatty acids, endothelial cells, medium-chain triglyceride:fish oil emulsion concentration-response relationship for the incorporation of $\omega 3$ fatty acids in the phospholipids of cultured endothelial cells exposed to MCT:FO. For purpose of comparison, parallel experiments were conducted in endothelial cells exposed to either other emulsions, including a pure fish oil emulsion, or albumin-bound $\omega 3$ fatty acids.

\section{Materials and methods}

Four emulsions were tested in the present experiments. They consisted of a 8:2 medium-chain triglyceride:fish oil emulsion (MCT:FO), a 5:5 medium-chain triglyceride:fish oil emulsion (5:5), a 5:4:1 medium-chain triglyceride:longchain triglyceride:fish oil emulsion (5:4:1) and a pure fish oil emulsion (FO).

Bovine aortic endothelial cells (BAEC; Cambrex BioScience, Verviers, Belgium) or human umbilical venous endothelial cells (HUVEC; Cambrex BioScience) were cultured to confluence in gelatine-coated Petri dishes in DMEM medium (61965-059; In Vitrogen, Brussels, Belgium) containing $10 \%$ (v:v) foetal bovine serum (10106-169; In Vitrogen) and $1 \%(\mathrm{v}: \mathrm{v})$ of a solution of penicillin and streptomycin (15070-063; In Vitrogen).

In order to mimic in vivo conditions, the lipid emulsions were incubated in human plasma $\left(45 \mathrm{~min}\right.$ at $\left.25^{\circ} \mathrm{C}\right)$ at a triglyceride concentration of $2.5 \mathrm{mg} / \mathrm{ml}$. The triglyceride-rich particles were then separated by ultracentrifugation (30 min; $2000 \mathrm{~g}$ ). The endothelial cells were supplied with bovine milk lipoprotein lipase ( $8 \mu \mathrm{g} / \mathrm{ml}$; L2254; Sigma-Aldrich, Bornem, Belgium) over $30 \mathrm{~min}$ of incubation at $20^{\circ} \mathrm{C}$. The emulsions were then added to the cell culture medium, which contained $30 \mathrm{mg} / \mathrm{ml}$ fatty acid free bovine serum albumin (BSA; A8806; Sigma-Aldrich), at final concentrations cited in the text. Further incubations were conducted at $37^{\circ} \mathrm{C}$. After incubation, the endothelial cells were washed twice with BSA-containing DMEM or phosphate buffer saline (14190-169; In Vitrogen) prior to being detached by trypsin-EDTA (25200-056; In Vitrogen). Cell phospholipids and triglycerides were separated by thin layer chromatography, and their fatty acid pattern determined by gas liquid chromatography (4).

All results are presented as mean values $( \pm$ SEM) together with the number of individual determinations ( $n$ ). The statistical significance of differences between mean values was assessed by use of the Student's t-test. 
Table I. Weight percentage of different fatty acids in the phospholipids of HUVEC cells exposed for $4 \mathrm{~h}$ to $\mathrm{MCT}$ :FO (0.5 mg/ml) and, when required, further cultured for 20 or $44 \mathrm{~h}$ in its absence. ${ }^{\mathrm{a}}$

\begin{tabular}{|c|c|c|c|c|c|c|}
\hline \multirow{2}{*}{$\begin{array}{l}\text { Culture } \\
\text { (h) }\end{array}$} & \multirow[t]{2}{*}{ Emulsion } & \multicolumn{5}{|c|}{ Weight percentage in phospholipid } \\
\hline & & C16:0 & C18:1w9 & C20:5w3 & $\mathrm{C} 22: 5 \omega 3$ & C22:6w3 \\
\hline \multirow[t]{2}{*}{4} & Control & 27.8 & 25.3 & 0.0 & 2.7 & 4.4 \\
\hline & MCT:FO & $25.4 \pm 0.2$ & $22.5 \pm 0.5$ & $4.6 \pm 0.1$ & $3.8 \pm 0.1$ & $6.2 \pm 0.1$ \\
\hline \multirow[t]{2}{*}{24} & Control & 28.3 & 25.4 & 0.0 & 2.9 & 4.5 \\
\hline & MCT:FO & $28.1 \pm 0.1$ & $20.1 \pm 0.4$ & $3.7 \pm 0.2$ & $6.4 \pm 0.2$ & $7.0 \pm 0.2$ \\
\hline \multirow[t]{2}{*}{48} & Control & 28.6 & 26.5 & 0.0 & 2.5 & 3.9 \\
\hline & MCT:FO & $29.3 \pm 0.3$ & $19.9 \pm 0.2$ & $3.0 \pm 0.1$ & $7.2 \pm 0.2$ & $7.0 \pm 0.1$ \\
\hline
\end{tabular}

${ }^{a}$ Mean values ( \pm range of individual variation) refer to two separate observations. The measurements made in cells not exposed to MCT:FO are indicated as control values.

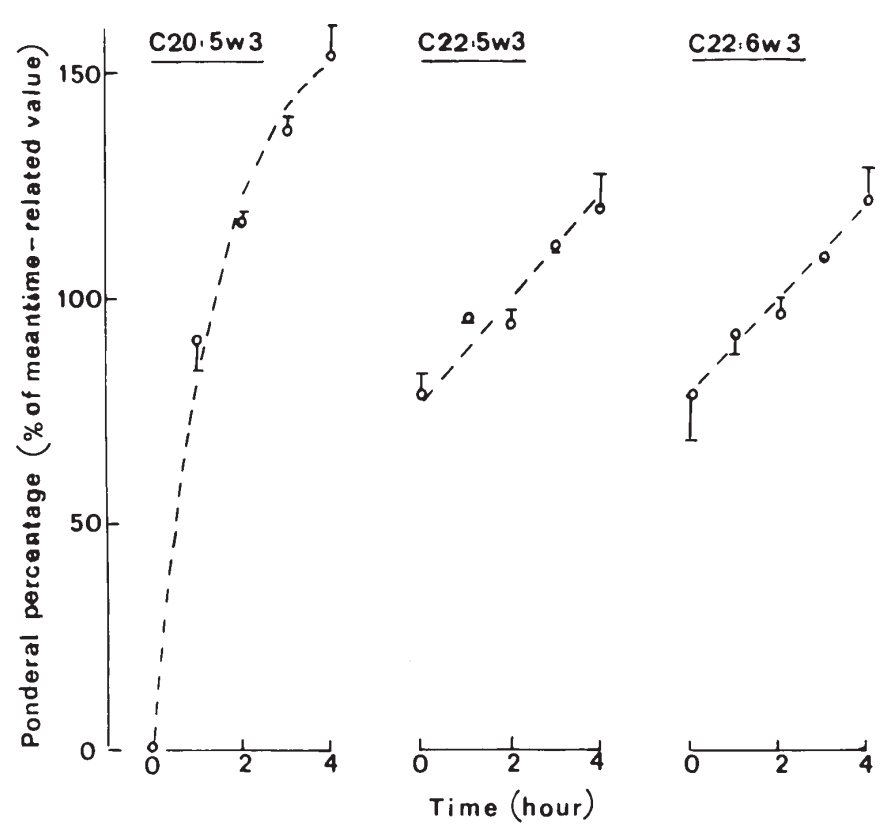

Figure 1. Time course for the increase of the weight percentage of C20:5 133 (left), C22:5 13 (middle) and C22:6w3 (right) in the phospholipids of HUVEC cells exposed to 0.5 or $2.5 \mathrm{mg} / \mathrm{ml} \mathrm{MCT:FO.} \mathrm{Mean} \mathrm{values} \mathrm{(} \pm$ range of individual variation) refer to the results obtained at the two concentrations of MCT:FO and are expressed in percent of the mean value derived from the five successive measurements made for each fatty acid at each concentration of MCT:FO. Such reference values averaged, when expressed as a weight percentage relative to the paired total amount of fatty acids present in phospholipids, $3.12 \pm 0.14 \%$ in the case of $\mathrm{C} 20: 5 \omega 3,2.86 \pm 0.12 \%$ in the case of $\mathrm{C} 22: 5 \omega 3$ and $4.42 \pm 0.48 \%$ in the case of $\mathrm{C} 22: 6 \omega 3$.

\section{Results}

Time course for the incorporation of long-chain polyunsaturated $\omega 3$ fatty acids in the phospholipids of endothelial cells. In order to investigate the time course for the incorporation of long-chain polyunsaturated $\omega 3$ fatty acids from the MCT:FO emulsion into the phospholipids of endothelial cells (HUVEC), these cells were exposed for 60, 120, 180 and $240 \mathrm{~min}$ to either $0.5 \mathrm{mg} / \mathrm{ml}$ or $2.5 \mathrm{mg} / \mathrm{ml} \mathrm{MCT:FO.}$
The total phospholipid content of the cells (expressed as fatty acid equivalent) was not affected significantly by the presence of the MCT:FO emulsion in the incubation medium, with an overall mean value of $123.8 \pm 4.5 \mu \mathrm{g}(\mathrm{n}=10)$. Likewise, the weight percentage of $\mathrm{C} 16: 0$ and $\mathrm{C} 18: 1 \omega 9$, the two most abundant fatty acids present in the cell phospholipids, was little affected during incubation, with overall mean respective values of $27.2 \pm 0.4$ and $23.2 \pm 0.5 \%$ ( $n=10$ in both cases).

The weight percentage of $\mathrm{C} 20: 5 \omega 3, \mathrm{C} 22: 5 \omega 3$ and $\mathrm{C} 26: 5 \omega 3$ was always higher than the basal value found in cells not exposed to MCT:FO. Except after $240 \mathrm{~min}$ of incubation, the phospholipid relative content (weight percentage) of C20:5 23 , $\mathrm{C} 22: 5 \omega 3$ and $\mathrm{C} 26: 5 \omega 3$ was consistently higher in the cells exposed to 2.5 as compared to $0.5 \mathrm{mg} / \mathrm{ml}$, MCT:FO. Pooling all available data, the paired ratios between the measurements made after the same incubation time and relative to the same long-chain polyunsaturated $\omega 3$ fatty acid at the high/low concentration of the lipid emulsion averaged $112.5 \pm 2.9 \% \quad(n=2$; $\mathrm{P}<0.005$ versus unity). There was a significant inverse correlation $(\mathrm{r}=-0.6025$; d.f.=10; $\mathrm{P}<0.05)$, however, between such paired ratios and the length of incubation.

The time course for the enrichment of cell phospholipids in each long-chain polyunsaturated $\omega 3$ fatty acid was not identical in all cases. In the case of C20:5 03 , the time course displayed downward concavity and was compatible with the equation $\mathrm{C}=\mathrm{C}_{\max } \mathrm{e}^{-\mathrm{Kt}}$ in which $\mathrm{C}$ represents the content in $\mathrm{C} 20: 5 \omega 3$ at time $\mathrm{t} ; \mathrm{C}_{\max }$, the value for $\mathrm{C}$ under steady-state conditions; and $\mathrm{K}$, the fractional turnover rate, the latter being $~ 0.012 \mathrm{~min}^{-1}$ (Fig. 1). In the case of $\mathrm{C} 22: 5 \omega 3$ and $\mathrm{C} 22: 6 \omega 3$, however, the time-related increase in their weight percentage was grossly proportional to the length of incubation, at least over the period of $240 \mathrm{~min}$ under consideration, with mean hourly increments of $10.6 \pm 0.9$ and $11.7 \pm 2.1 \%$ ( $n=4$ in both cases), according to the mode of expression for the experimental results used in Fig. 1.

Stability of $\omega 3$ fatty acid incorporation in endothelial cell phospholipids. After $4 \mathrm{~h}$ of incubation in the presence of MCT:FO $(0.5 \mathrm{mg} / \mathrm{ml})$, the C20:5 33 content of HUVEC phospholipids increased $(\mathrm{P}<0.001)$ from a control value (no 
Table II. Absolute total amounts and relative contribution of selected fatty acids in the phospholipids and triglycerides of HUVEC cells exposed for 240 min to increasing concentrations of MCT:FO (8:2).

\begin{tabular}{|c|c|c|c|c|}
\hline MCТ:FO $(\mu \mathrm{g} / \mathrm{ml})$ & Nil & 100 & 250 & 500 \\
\hline \multicolumn{5}{|l|}{ Phospholipids } \\
\hline Total $(\mu \mathrm{g})$ & $162.9(1)$ & $201.5 \pm 7.3(3)$ & $220.1 \pm 1.9(3)$ & $218.0 \pm 1.9(2)$ \\
\hline C16:0 (\%) & $33.5(1)$ & $28.8 \pm 0.5(3)$ & $27.0 \pm 0.2(3)$ & $25.8 \pm 0.6(2)$ \\
\hline $\mathrm{C} 18: 1 \omega 9(\%)$ & $25.9(1)$ & $23.7 \pm 0.2(3)$ & $22.7 \pm 0.1(3)$ & $22.0 \pm 0.2(2)$ \\
\hline $\mathrm{C} 20: 5 \omega 3(\%)$ & $0.0(1)$ & $3.0 \pm 0.1(3)$ & $3.8 \pm 0.0(3)$ & $4.4 \pm 0.0(2)$ \\
\hline C22:503 (\%) & $0.9(1)$ & $2.3 \pm 0.2(3)$ & $2.8 \pm 0.0(3)$ & $3.3 \pm 0.1(2)$ \\
\hline C22:6w3 (\%) & $1.4(1)$ & $3.5 \pm 0.7(3)$ & $4.7 \pm 0.1(3)$ & $5.6 \pm 0.3(2)$ \\
\hline \multicolumn{5}{|l|}{ Triglycerides } \\
\hline Total $(\mu \mathrm{g})$ & $2.61(1)$ & $7.24 \pm 0.13(3)$ & $21.94 \pm 0.22$ (3) & $48.93 \pm 0.68(2)$ \\
\hline C16:0 (\%) & $65.3(1)$ & $39.5 \pm 1.3(3)$ & $21.8 \pm 0.4(3)$ & $15.6 \pm 0.2(2)$ \\
\hline $\mathrm{C} 18: 1 \omega 9(\%)$ & $24.7(1)$ & $19.9 \pm 0.2(3)$ & $22.0 \pm 0.2(3)$ & $6.3 \pm 0.2(2)$ \\
\hline $\mathrm{C} 20: 5 \omega 3(\%)$ & $0.0(1)$ & $0.0 \pm 0.0$ & $7.9 \pm 0.3(3)$ & $13.5 \pm 0.4(2)$ \\
\hline $\mathrm{C} 22: 5 \omega 3(\%)$ & $0.0(1)$ & $11.5 \pm 0.1(3)$ & $12.7 \pm 0.2(3)$ & $13.3 \pm 0.1(2)$ \\
\hline C22:6w3 (\%) & $0.0(1)$ & $10.7 \pm 0.5(3)$ & $13.6 \pm 0.2(3)$ & $16.7 \pm 0.1(2)$ \\
\hline
\end{tabular}

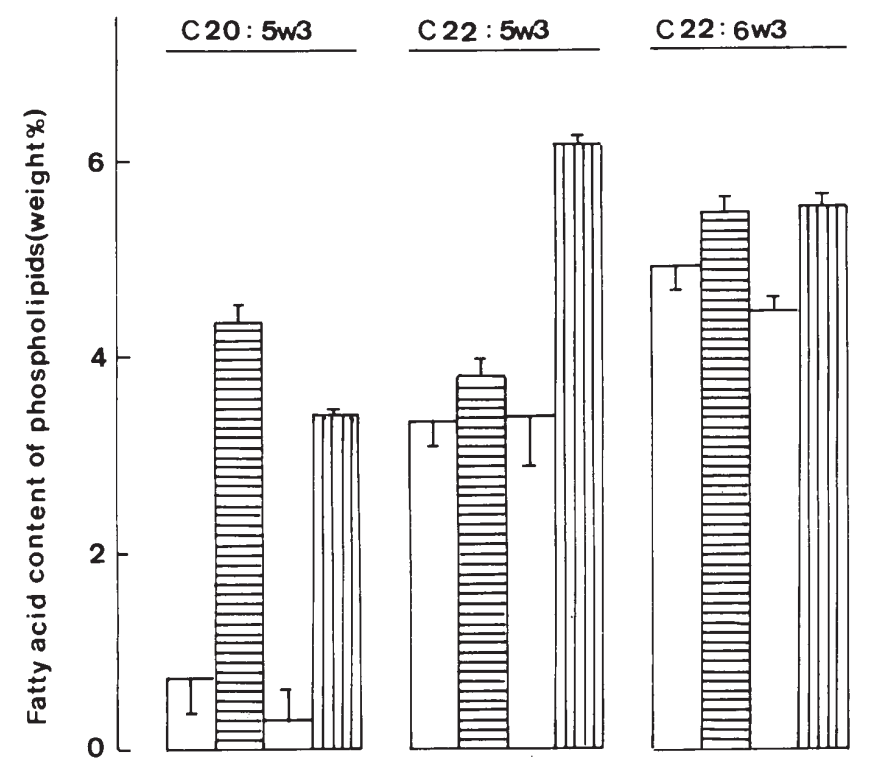

Figure 2. Content of $\omega 3$ fatty acids in phospholipids of HUVEC incubated for $4 \mathrm{~h}$ (left columns) in the absence (open columns) or presence (hatched columns) of MCT-FO and then further incubated for $20 \mathrm{~h}$ in the absence of MCT:FO (right columns). Mean values ( \pm SEM) refer to 3 (open columns) or 7 (hatched columns) individual determinations.

MCT:FO) of $0.73 \pm 0.37 \%(n=3)$ to $4.36 \pm 0.19 \%(n=7)$. After a further $20 \mathrm{~h}$ of incubation in the absence of MCT:FO, such a content was decreased $(\mathrm{P}<0.001)$ to a mean value of $3.43 \pm$ $0.04 \%(\mathrm{n}=7)$, which remained much higher $(\mathrm{P}<0.001)$ than that recorded at the same time in cells never exposed to MCT:FO (Fig. 2).

Likewise, after $4 \mathrm{~h}$ of incubation in the presence of MCT:FO, the C22:5 23 content of HUVEC was $0.65 \pm 0.03 \%$ (d.f.=6; $\mathrm{P}<0.001$ ) higher than the corresponding mean control value found within the same experiments $(3.37 \pm 0.28 \% ; \mathrm{n}=3)$. It further increased $(\mathrm{P}<0.001)$ from $3.83 \pm 0.19$ to $6.19 \pm 0.07 \%$ $(n=7$ in both cases) when the endothelial cells were then incubated for $20 \mathrm{~h}$ in the absence of MCT:FO.

In the case of $\mathrm{C} 22: 6 \mathrm{\omega} 3$, the increase above the control value $(4.93 \pm 0.23 \% ; \mathrm{n}=3)$ after $4 \mathrm{~h}$ of exposure to MCT:FO averaged $0.65 \pm 0.13 \%$ (d.f. $=6 ; \mathrm{P}<0.005$ ). No further significant change $(\mathrm{P}>0.75)$ was observed during the $20 \mathrm{~h}$ incubation in the absence of MCT:FO. The C22:6 33 content of cell phospholipids averaged $5.49 \pm 0.13$ and $5.54 \pm 0.14 \%$ ( $n=7$ in both cases) at the onset and end of this incubation.

In light of these findings, a further experiment was conducted in which the HUVEC were exposed to the MCT:FO emulsion $(0.5 \mathrm{mg} / \mathrm{ml})$ for $4 \mathrm{~h}$ and then cultured for 20 or $44 \mathrm{~h}$ in its absence. The results of this experiment are summarized in Table I. They indicate that the weight percentage of C20:5 23 in the cell phospholipids slowly declined during the $44 \mathrm{~h}$ of culture in the absence of MCT:FO, whilst remaining much higher than basal value. The phospholipid content in

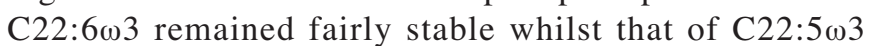
displayed a progressive increase over the same 44-h period.

Concentration-response relationship in endothelial cells exposed to MCT:FO. In an initial experiment, HUVEC cells were exposed for $240 \mathrm{~min}$ to increasing concentrations of MCT:FO in the 100 to $500 \mu \mathrm{g} / \mathrm{ml}$ range. Expressed as fatty acids, the total amount of phospholipids extracted from the HUVEC cells after $4 \mathrm{~h}$ of incubation in the presence of the MCT:FO emulsion $(212.6 \pm 4.1 \mu \mathrm{g} ; \mathrm{n}=8)$ failed to differ significantly in the cells exposed to increasing concentrations of this lipid emulsion (Table II). Likewise, the relative contribution of $\mathrm{C} 16: 0$ and $\mathrm{C} 18: 1 \omega 9$, selected as the two most abundant fatty acids present in the phospholipids, displayed only minor changes in the cells exposed to increasing 
Table III. Phospholipid and triglyceride content and composition in HUVEC cells exposed for 240 min to different lipid emulsions $(0.5 \mathrm{mg} / \mathrm{ml})$.

\begin{tabular}{|c|c|c|c|c|c|}
\hline Emulsion & Blank & $5: 4: 1$ & MCT:FO & FO & $5: 5$ \\
\hline \multicolumn{6}{|l|}{ Phospholipids } \\
\hline Total $(\mu \mathrm{g})$ & $204.8 \pm 13.5(7)$ & $222.4 \pm 13.4(9)$ & $224.1 \pm 9.2(9)$ & $214.0 \pm 11.4(9)$ & $222.7 \pm 10.2(6)$ \\
\hline $\mathrm{C} 16: 0(\mu \mathrm{g})$ & $56.49 \pm 3.58(7)$ & $55.24 \pm 3.34(9)$ & $56.43 \pm 2.34(9)$ & $56.62 \pm 3.09(9)$ & $55.48 \pm 2.90(6)$ \\
\hline 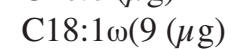 & $54.65 \pm 3.79(7)$ & $52.02 \pm 3.43(9)$ & $52.39 \pm 2.64(9)$ & $48.95 \pm 2 / 94(9)$ & $49.87 \pm 3.40(6)$ \\
\hline $\mathrm{C} 18: 2 \omega 6(\mu \mathrm{g})$ & $6.79 \pm 0.33(7)$ & $24.56 \pm 1.38(9)$ & $8.52 \pm 0.27(9)$ & $7.23 \pm 0.29(9)$ & $8.16 \pm 0.28$ \\
\hline $\mathrm{C} 20: 5 \omega 3(\mu \mathrm{g})$ & $0.81 \pm 0.29(7)$ & $4.54 \pm 0.25(9)$ & $10.06 \pm 0.34(9)$ & $11.41 \pm 0.54(9)$ & $12.96 \pm 0.64(6)$ \\
\hline $\mathrm{C} 22: 5 \omega 3(\mu \mathrm{g})$ & $5.10 \pm 0.29(7)$ & $6.31 \pm 0.38(9)$ & $7.71 \pm 0.33(9)$ & $7.32 \pm 0.36(9)$ & $7.87 \pm 0.24(6)$ \\
\hline $\mathrm{C} 22: 6 \omega 3(\mu \mathrm{g})$ & $7.86 \pm 0.50(7)$ & $9.92 \pm 0.84(9)$ & $11.96 \pm 0.47(9)$ & $10.03 \pm 0.45(9)$ & $12.32 \pm 0.48(6)$ \\
\hline \multicolumn{6}{|l|}{ Triglycerides } \\
\hline Total $(\mu \mathrm{g})$ & $5.23 \pm 0.47(7)$ & $42.08 \pm 3.23(9)$ & $31.96 \pm 0.97(9)$ & $28.27 \pm 1.73(9)$ & $46.18 \pm 2.19(6)$ \\
\hline $\mathrm{C} 16: 0(\mu \mathrm{g})$ & $1.47 \pm 0.50(7)$ & $6.33 \pm 0.68(9)$ & $5.57 \pm 0.56(9)$ & $5.92 \pm 0.73(9)$ & $6.11 \pm 1.15$ \\
\hline $\mathrm{C} 18: 1 \omega 9(\mu \mathrm{g})$ & $0.95 \pm 0.49(7)$ & $9.88 \pm 0.74(9)$ & $7.08 \pm 0.27(9)$ & $4.93 \pm 0.72(9)$ & $9.22 \pm 0.53(6)$ \\
\hline $\mathrm{C} 18: 2 \omega 6(\mu \mathrm{g})$ & $0.00 \pm 0.00(7)$ & $13.05 \pm 1.20(9)$ & $2.27 \pm 0.10(9)$ & $0.56 \pm 0.28(9)$ & $2.99 \pm 0.12(6)$ \\
\hline $\mathrm{C} 20: 5 \omega 3(\mu \mathrm{g})$ & $0.00 \pm 0.00(7)$ & $2.13 \pm 0.24(9)$ & $3.59 \pm 0.24(9)$ & $4.90 \pm 0.25(9)$ & $7.44 \pm 0.36(6)$ \\
\hline $\mathrm{C} 22: 5 \omega 6(\mu \mathrm{g})$ & $0.00 \pm 0.00(7)$ & $2.76 \pm 0.27$ (9) & $3.98 \pm 0.21(9)$ & $3.32 \pm 0.19(9)$ & $6.82 \pm 0.25(6)$ \\
\hline $\mathrm{C} 22: 6 \omega 3(\mu \mathrm{g})$ & $0.00 \pm 0.00(7)$ & $2.96 \pm 0.29(9)$ & $4.84 \pm 0.24(9)$ & $3.27 \pm 0.15(9)$ & $8.03 \pm 0.32(6)$ \\
\hline
\end{tabular}

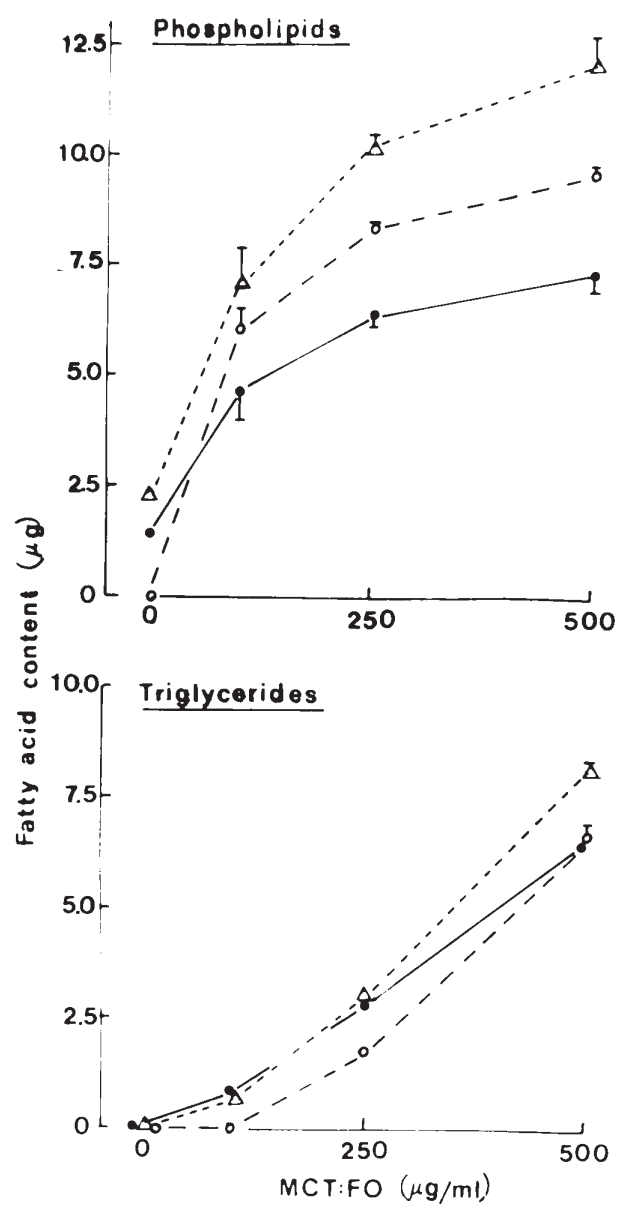

Figure 3. Content of phospholipids (upper panel) and triglycerides (lower panel) in $\mathrm{C} 20: 5 \omega 3$ (open circles and dashed line), $\mathrm{C} 22: 5 \omega 3$ (closed circles and solid line) and C22:6w3 (open triangles and dotted line) in HUVEC cells exposed for $240 \mathrm{~min}$ to increasing concentrations of MCT:FO. Mean values ( \pm SEM, whenever exceeding the size of the mean point) refer to one (control cells not exposed to MCT:FO) or 2-3 (cells exposed to MCT:FO) separate determinations. concentrations of MCT:FO. In the case of C20:5 $23, \mathrm{C} 22: 5 \omega 3$ and $\mathrm{C} 22: 6 \omega 3$, however, such a relative contribution was not only much higher after incubation in the presence, as distinct from the absence, of MCT:FO, but also progressively increased as a function of the concentration of the latter emulsion present in the incubation medium.

A different situation was found in the case of the triglycerides extracted from the HUVEC cells. The absolute total amount of these triglycerides, also expressed as fatty acids, increased, almost in proportion to the concentration of MCT:FO in the incubation medium. The total amount of C16:0 also increased from a basal value of $1.70 \mu \mathrm{g}$ to $2.86 \pm 0.04 \mu \mathrm{g}$, $4.79 \pm 0.10 \mu \mathrm{g}$ and $7.62 \pm 0.03 \mu \mathrm{g}(\mathrm{n}=2-3)$ after exposure to increasing concentrations of MCT:FO. Likewise, the total amount of $\mathrm{C} 18: 1 \omega 9$ increased, under the same experimental conditions, from a basal value of $0.91 \mu \mathrm{g}$ to $1.44 \pm 0.01 \mu \mathrm{g}$, $4.82 \pm 0.05 \mu \mathrm{g}$ and $7.93 \pm 0.04 \mu \mathrm{g}(\mathrm{n}=2-3)$. In relative terms, however, the contribution of $\mathrm{C} 16: 0$ and $\mathrm{C} 18: 1 \omega 9$ was much lower after incubation in the presence, as compared to absence, of MCT:FO. This situation was mainly attributable to the appearance in triglycerides of other fatty acids such as

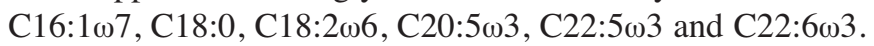
The enrichment of triglycerides by the long-chain polyunsaturated $\omega 3$ fatty acids was, in absolute terms, closely related to the concentration of MCT:FO in the incubation medium, but with distinct threshold levels, for $\mathrm{C} 20: 5 \mathrm{\omega} 3$, on

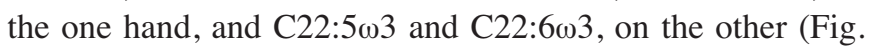
3 ). The curve defining the concentration dependency for such an enrichment displayed upward concavity, in sharp contrast to the pattern found for the accumulation of long-chain polyunsaturated $\omega 3$ fatty acids in phospholipids.

The findings made in this first experiment led us to extend the same study to a higher range of MCT:FO concentration $(500-2,000 \mu \mathrm{g} / \mathrm{ml})$. Expressed as fatty acids, the total amount of phospholipids extracted from the endothelial cells again 


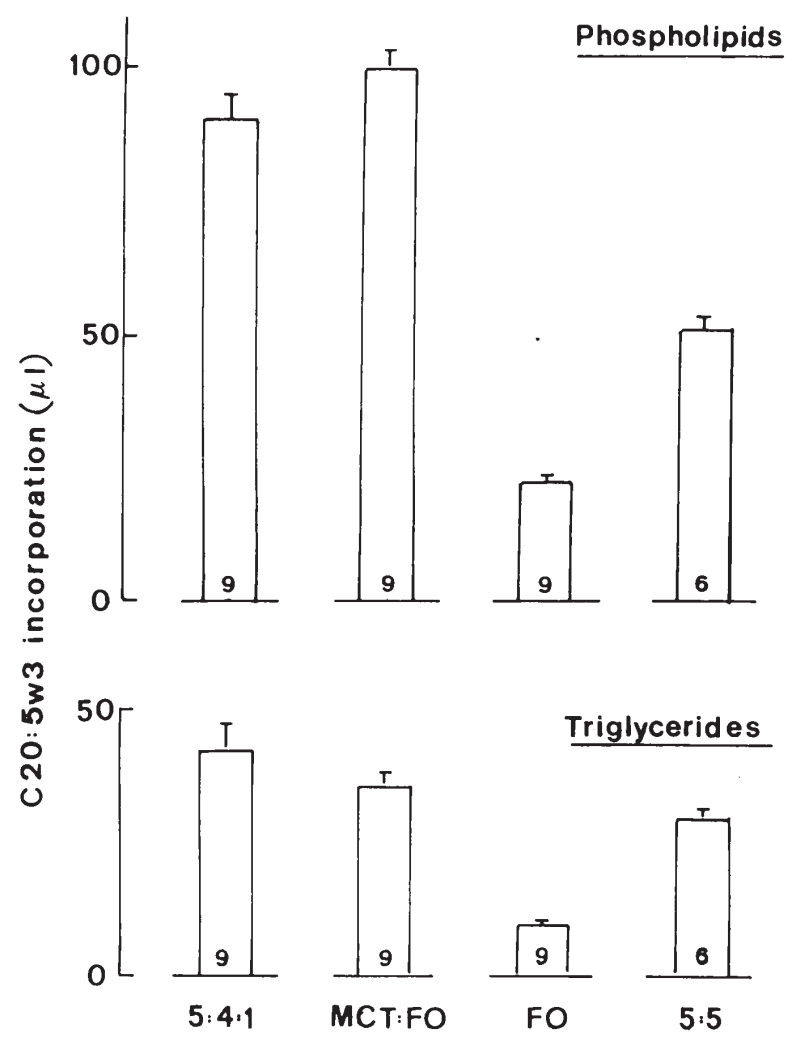

Figure 4. Efficiency of C20:5w3 incorporation in phospholipids and triglycerides of HUVEC cells exposed to four different lipid emulsions. Mean values $( \pm$ SEM) for the ratio between the C20:5 $\omega 3$ absolute content $(\mu \mathrm{g})$ of each lipid fraction and corresponding concentration of fish oil in the incubation medium are expressed as an apparent distribution space $(\mu 1)$ and refer to the number of individual determinations indicated at the bottom of each column.

failed to be affected by the concentration of MCT:FO. It averaged $187.9 \pm 5.1 \mu \mathrm{g}(\mathrm{n}=8)$, as compared to a basal value of $188.6 \pm 13.0 \mu \mathrm{g}(\mathrm{n}=3)$. The relative contribution of the two most abundant fatty acids in the phospholipids, i.e. C16:0 and C18:1w9, also failed to display any major change as a function of the concentration of MCT:FO present in the incubation medium, with overall mean respective values of $23.6 \pm 0.3$ and $22.3 \pm 0.5 \%(n=10$ in both cases $)$. Whether expressed in absolute terms or as a weight percentage, the amount of $\mathrm{C} 20: 5 \omega 3, \mathrm{C} 22: 5 \omega 3$ and $\mathrm{C} 22: 6 \omega 3$ present in the phospholipids was also little affected by the concentration of MCT:FO. For instance, after correction for basal value (cells not exposed to MCT:FO), the increment in the weight percentage of $\mathrm{C} 20: 5 \omega 3$ averaged $4.5 \pm 0.1,4.7 \pm 0.1$ and $4.8 \pm 0.1 \%(\mathrm{n}=2-3)$ in cells exposed to $0.5,1.0$ and $2.0 \mathrm{mg} / \mathrm{ml}$ MCT:FO. Likewise, the phospholipid content in C22:6w3 averaged $11.62 \pm 0.13 \mu \mathrm{g}(\mathrm{n}=2), 11.76 \pm 0.78 \mu \mathrm{g}(\mathrm{n}=3)$ and $12.86 \pm 0.56 \mu \mathrm{g}(\mathrm{n}=3)$ after incubation in the presence of 0.5 , 1.0 and $2.0 \mathrm{mg} / \mathrm{ml} \mathrm{MCT:FO.}$

Similar to the first experiment, the absolute total amount of triglycerides, expressed as fatty acids, increased virtually in proportion to the concentration of MCT:FO, with an overall mean value of $58.9 \pm 3.0 \mu 1(\mathrm{n}=8)$ for the paired ratio between triglyceride content $(\mu \mathrm{g})$ and $\mathrm{MCT}: \mathrm{FO}$ concentration $(\mu \mathrm{g} / \mathrm{ml})$. Also in agreement with the first experiment, the

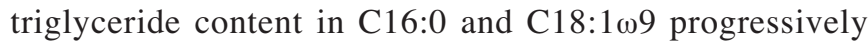

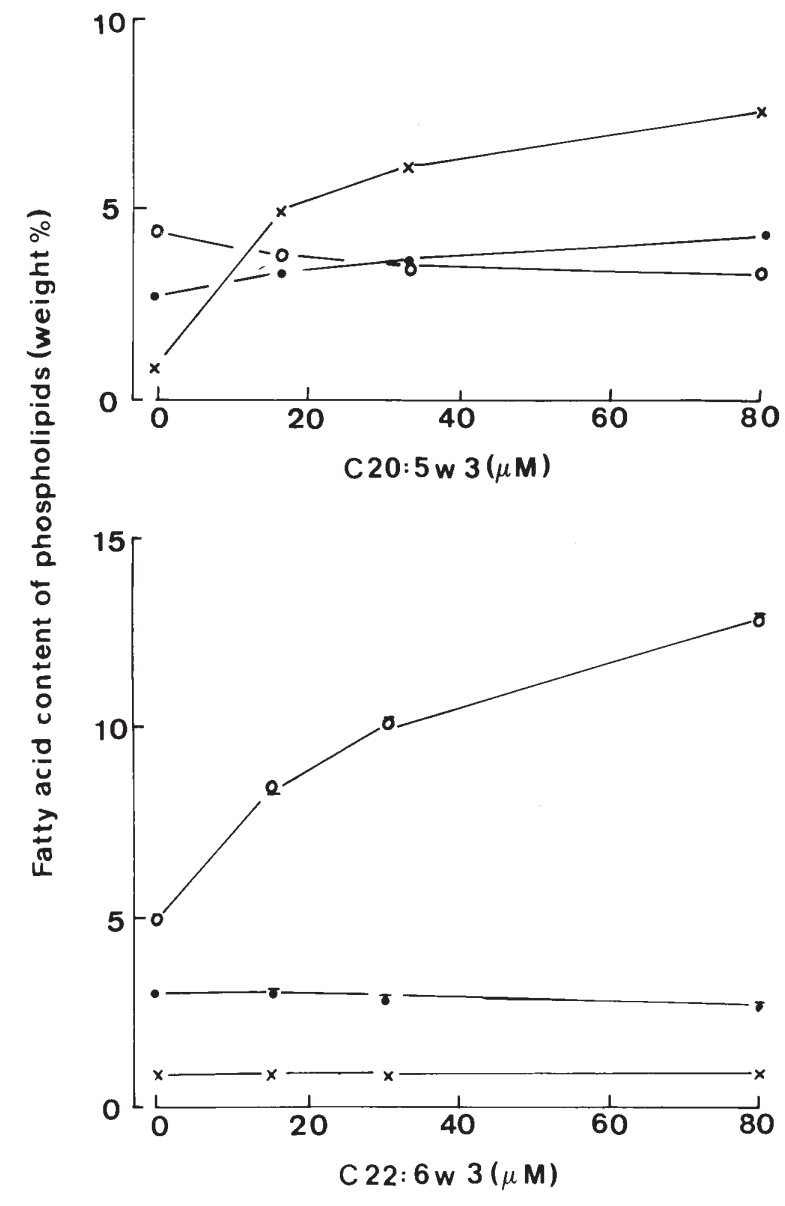

Figure 5. C20:5 $\omega 3$ (crosses), C22:5 33 (closed circles) and $\mathrm{C} 22: 6 \omega 3$ (open circles) content of phospholipids in BAEC exposed for $4 \mathrm{~h}$ to increasing concentrations of either C20:5 33 (upper panel) or C22:6w3 (lower panel) Mean values ( \pm SEM, when exceeding the size of the mean point) refer to 3 individual determinations in the cells exposed to an exogenous fatty acid.

increased in absolute terms, but progressively decreased as a weight percentage with increasing concentrations of MCT:FO. The triglyceride content in long-chain polyunsaturated $\omega 3$ fatty acids, expressed in absolute terms, continued to increase as a function of the concentration of MCT:FO. For instance, that of C20:5 23 increased from $4.25 \pm 0.70 \mu \mathrm{g}(\mathrm{n}=2)$ to $10.79 \pm 0.39 \mu \mathrm{g}(\mathrm{n}=3)$ and $26.48 \pm 1.39 \mu \mathrm{g}$ $(\mathrm{n}=3)$ as the concentration of MCT:FO was raised from 0.5 to 1.0 and $2.5 \mathrm{mg} / \mathrm{ml}$. A comparable pattern was observed in the case of $\mathrm{C} 22: 5 \omega 3$ and $\mathrm{C} 22: 6 \omega 3$ with overall mean respective values of $6.88 \pm 0.35$ and $10.80 \pm 0.37 \mu \mathrm{l}(\mathrm{n}=8$ in both cases) for the paired ratio between their content $(\mu \mathrm{g})$ in the triglycerides and the MCT:FO concentration $(\mu \mathrm{g} / \mathrm{ml})$.

Collectively, these findings indicate that, from the perspective of enriching cell phospholipids in the long-chain polyunsaturated $\omega 3$ fatty acids, there is little benefit to be expected from an increase in MCT:FO concentration above $\sim 0.5 \mathrm{mg} / \mathrm{ml}$. The triglyceride content in these $\omega 3$ fatty acids, however, increases almost in proportion to the concentration of MCT:FO in the $0.1-2.5 \mathrm{mg} / \mathrm{ml}$ range. Such is also the case for the total triglyceride content of the endothelial cells. This information is most relevant to the clinical case of the MCT:FO emulsion. For instance, in the first study conducted in normal human subjects, the bolus intravenous injection of $10 \mathrm{~g}$ of 


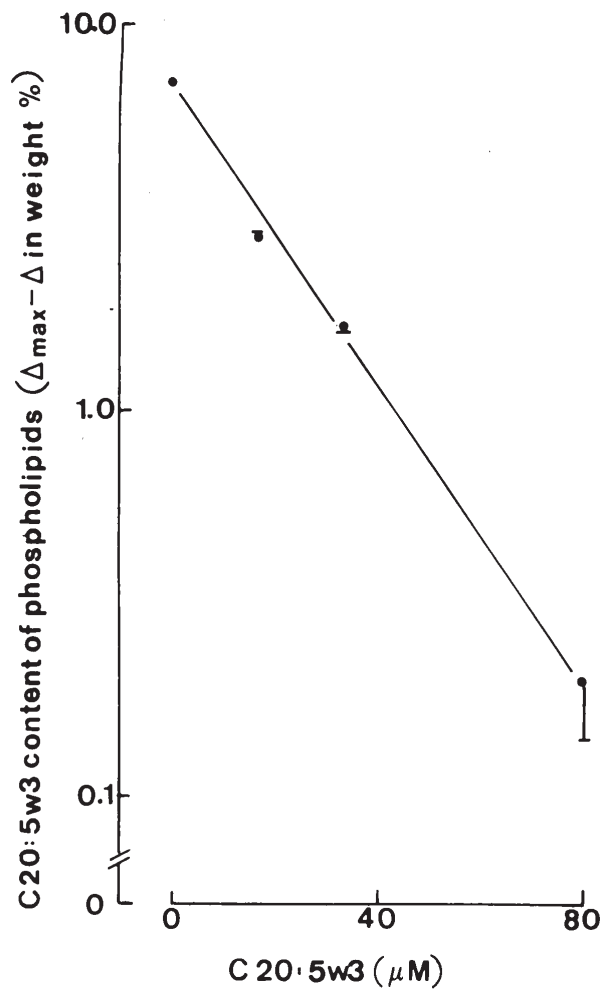

Figure 6 . The difference between the estimated maximal increment $\left(\Delta_{\max }\right)$ above basal value for the phospholipid content of $\mathrm{C} 20: 5 \omega 3$ (weight $\%$ ) in BAEC exposed for $4 \mathrm{~h}$ to increasing concentrations of the same fatty acid. The observed increment $(\Delta)$ is plotted on a logarithmic scale as a function of the extracellular concentration of C20:5 03 (cartesian scale). The experimental data correspond to those illustrated in Fig. 5.

MCT:FO, given as $50 \mathrm{ml}$ of a $20 \%(\mathrm{w} / \mathrm{v})$ emulsion, resulted in an increase in plasma triglyceride concentration corresponding to an initial volume of distribution close to 4.0 liters, i.e. expressed in terms of MCT:FO concentration a value close to $2.5 \mathrm{mg} / \mathrm{ml}$, namely the highest concentration tested in the present set of experiments.

Comparison between different emulsions. After $240 \mathrm{~min}$ of incubation in the presence of different lipid emulsions at a $0.5 \mathrm{mg} / \mathrm{ml}$ concentration, the total amount of phospholipids extracted from the HUVEC endothelial cells was comparable in all cases (Table III). Likewise, the amount of C16:0 and C18:1 19 present in the phospholipids was similar in all cases. These two fatty acids were the most abundant among all fatty acids present in the phospholipids and represented each, as a weight percentage, $22-28 \%$ of the total fatty acid content of the phospholipids. Whether expressed in absolute terms $(\mu \mathrm{g})$ or as a weight percentage, the amount of C18:2 $\omega 6$ present in the phospholipids was much higher, however, in the cells exposed to the 5:4:1 emulsion than in either the control cells (not exposed to any emulsion) or those exposed to the other three lipid emulsions. The absolute amounts of the long-chain polyunsaturated $\omega 3$ fatty acids (C20:5 $\omega 3, \mathrm{C} 22: 5 \omega 3$ and $\mathrm{C} 22: 6 \omega 3)$ recovered in the phospholipids exceeded the basal value found in control cells. It was lower in the cells exposed to the 5:4:1 emulsion than in cells exposed to the other three emulsions, in which case the results were not vastly different from one another. There was a close parallelism between the $\mathrm{C} 22: 5 \omega 3$ and $\mathrm{C} 22: 6 \omega 3$ measurements, the mean value for $\mathrm{C} 22: 5 \omega 3$ averaging $66.0 \pm 1.8 \%(\mathrm{n}=5)$ of the mean corresponding value for $\mathrm{C} 22: 6 \mathrm{w} 3$.

As illustrated in Fig. 4, when the amount of C20:5 13 present in the phospholipids was divided by the concentration of fish oil in the incubation medium, the mean relative efficiency for the incorporation of C20:5 03 in the phospholipids was highest with the MCT:FO emulsion, being comparable $(\mathrm{P}>0.1)$ to that found with the 5:4:1 emulsion but 2-5 times higher than that found with the 5:5 and FO emulsion, respectively.

A somewhat different situation prevailed in the case of the triglycerides extracted from the endothelial cells. First, the total amount of triglycerides, expressed as fatty acid equivalent, was much higher $(\mathrm{P}<0.001)$ after incubation in the presence, than in the absence of a lipid emulsion. Second, and most important, such a total triglyceride content was not significantly different $(\mathrm{P}>0.075)$ in the cells exposed to either the MCT:FO or pure fish oil emulsion and, in both cases, sizeably lower $(\mathrm{P}<0.01$ or less $)$ than that found in cells exposed to either the $5: 4: 1$ or $5: 5$ emulsion (Table III). Third, in the case of the lipid emulsions containing medium-chain fatty acid triglycerides, the amount of long-chain polyunsaturated $\omega 3$ fatty acids recovered in the cell triglycerides was grossly proportional to the concentration of fish oil in the incubation medium and, relative to the latter concentration, much higher than in cells exposed to the pure FO emulsion (Table III). For instance, in the case of $\mathrm{C} 20: 5 \omega 3$, the ratio between its content $(\mu \mathrm{g})$ in cell triglycerides and the concentration of fish oil in the incubation medium was not significantly different in cells exposed to the MCT:FO emulsion, as compared to either the 5:4:1 $(\mathrm{P}>0.2)$ or 5:5 emulsion ( $\mathrm{P}>0.05)$, with an overall mean value of $36.8 \pm 2.2 \mu 1$ $(\mathrm{n}=24)$ as distinct $(\mathrm{P}<0.001)$ from only $9.8 \pm 0.5 \mu \mathrm{l}(\mathrm{n}=9)$ in the cells exposed to the pure FO emulsion (Fig. 4).

In analogy with the findings relative to the composition of

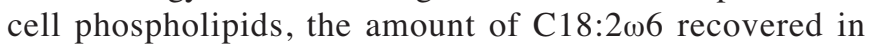
triglycerides was much higher $(\mathrm{P}<0.001)$ in the cells exposed for 5:4:1 than the other three emulsions. The content of cell triglycerides in $\mathrm{C} 16: 0$ was comparable $(\mathrm{P}>0.4)$ with the four tested lipid emulsions. That of $\mathrm{C} 18: 1 \omega 9$ followed a pattern grossly comparable to that defined above for the total amount of cell triglycerides with, however, a lower value $(\mathrm{P}<0.02$ or less) in cells exposed to the FO emulsion as compared to the other three lipid emulsions.

Experiments with albumin-bound $\omega 3$ fatty acids. In the next experiments, the incorporation of C20:5 13 in BAEC phospholipids was measured over $240 \mathrm{~min}$ of incubation in the presence of $16.6,33.1$ and $80.0 \mu \mathrm{M}$ of the albumin-bound fatty acid. Likewise, the incorporation of C22:6w3 in BAEC phospholipids was measured over the same time in the presence of $15.2,30.5$ and $80.0 \mu \mathrm{M}$ of the albumin-bound docosahexaenoic acid. The selection of these concentrations was motivated by the following considerations. The two lowest concentrations were close to those of C20:5 $33(\sim 17.6 \mu \mathrm{M})$

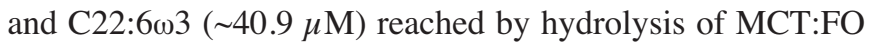
$(0.5 \mathrm{mg} / \mathrm{ml}$ or $0.94 \mathrm{mM})$. The highest concentration was closer to the calculated molar amount of these fatty acids (70-76 $\mu \mathrm{M})$ in $0.94 \mathrm{mM} \mathrm{MCT:FO.}$ 


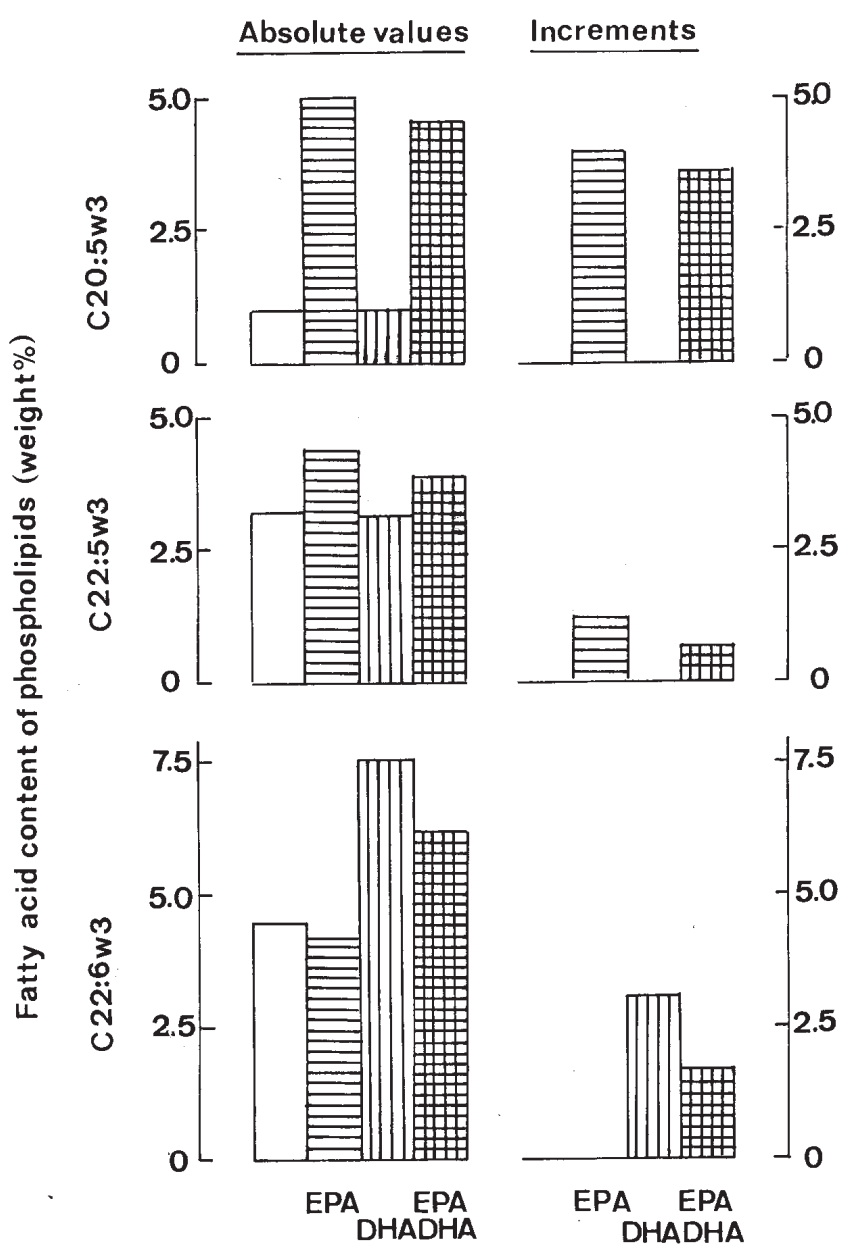

Figure 7. Absolute values (left) and increments above basal value (right) for the $\mathrm{C} 20: 5 \omega 3$ (upper panel), $\mathrm{C} 22: 5 \omega 3$ (middle panel) and $\mathrm{C} 22: 6 \omega 3$ (lower panel) content of phospholipids in endothelial cells exposed for $4 \mathrm{~h}$ to 16.6

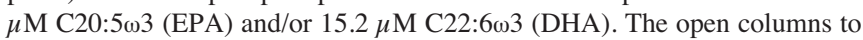
the left refer to the basal values.

In the cells exposed to increasing concentrations of C20:5 $\omega 3$, the relative phospholipid content in this fatty acid increased from a basal value $\sim 0.89$ (weight $\%$ ) to $4.97 \pm 0.03$, $6.13 \pm 0.03$ and $7.60 \pm 0.06 \%$ (Fig. 5). As documented in Fig. 6, this concentration-response relationship was compatible with an exponential pattern in which the increment $(\Delta)$ in the C20:5 33 content of cell phospholipids would be related to the concentration $(\mathrm{C})$ of the fatty acid in the incubation medium by the equation $\Delta=\Delta_{\max }\left(1-\mathrm{e}^{-\mathrm{KC}}\right)$, in which $\Delta_{\max }$ is $\sim 7.0 \%$ and $\mathrm{K} \sim 0.044 \mu \mathrm{M}^{-1}$, yielding a half-maximal response at a $\mathrm{C} 20: 5 \omega 3$ concentration of $\sim 15 \mu \mathrm{M}$. The $\mathrm{C} 22: 5 \omega 3$ content of cell phospholipids also increased progressively from a basal value of $2.85 \pm 0.15(\mathrm{n}=2)$ to $3.33 \pm 0.03,3.70 \pm 0.06$ and $4.33 \pm 0.07 \%$ ( $n=3$ in each case). On the contrary, the relative content of phospholipids in $\mathrm{C} 22: 6 \mathrm{\omega} 3$ progressively decreased below its control value to $3.73 \pm 0.13,3.57 \pm 0.03$ and $3.33 \pm 0.03 \%(\mathrm{n}=3$ in each case $)$. In the cells exposed to increasing concentrations of C22:6w3, the C20:5 203 and 22:5 03 content of cell phospholipids remained close to their respective basal value averaging, respectively, $0.83 \pm 0.03$ and $2.81 \pm 0.07$ ( $n=9$ in both cases), whilst that of $C 22: 6 \omega 3$ increased

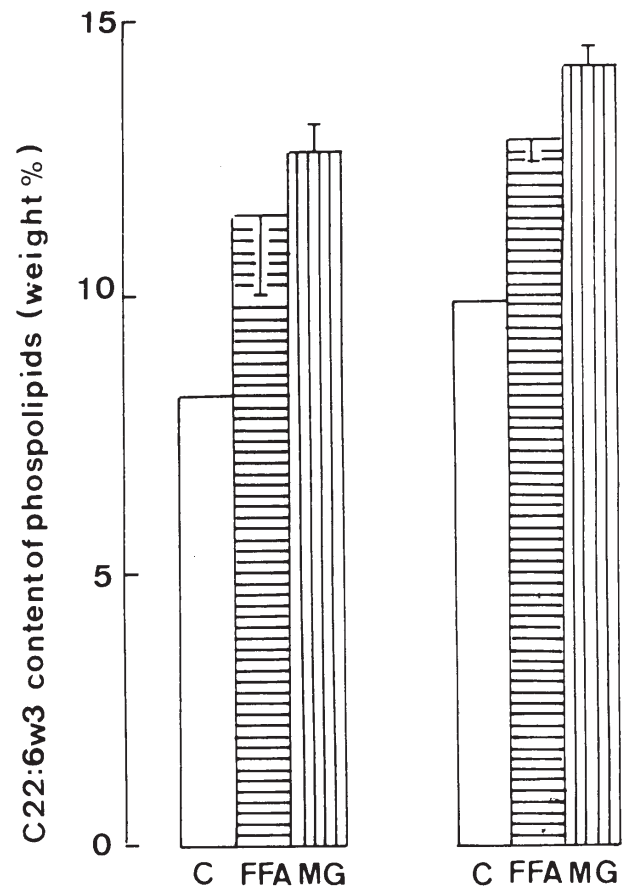

Figure 8. C22:6 13 content of phospholipids in BAEC exposed for $2 \mathrm{~h}$ (left) or 4 hours (right) to $15.2 \mu \mathrm{M} \mathrm{C} 22: 6 \omega 3$ (horizontally hatched columns) or its monoglyceride ester (vertically hatched columns). Mean values ( \pm SEM) refer to two individual measurements in each case. The open columns refer to the basal value for $\mathrm{C} 22: 6 \mathrm{w} 3$ in the cell phospholipids.

above its basal value (4.90\%), to $8.40 \pm 0.12,10.07 \pm 0.19$ and $12.80 \pm 0.21 \%(\mathrm{n}=3$ in each case).

The findings illustrated in Fig. 5 were confirmed in a further experiment in which exposure of the BAEC cells to C20:5 03 (16.6 and $80.0 \mu \mathrm{M})$ caused a concentration-related increment in the $\mathrm{C} 20: 5 \mathrm{\omega} 3$ content of phospholipids to 5.62 and 10.06 times its paired basal value (as compared to 6.21 and 9.50 times in Fig. 5) and also augmented the C22:5 33 content of phospholipids to $191 \%$ of the basal value). Within the same experiments, the $\mathrm{C} 20: 5 \omega 3$ and $\mathrm{C} 22: 5 \omega 3$ content of phospholipids in cells exposed for $240 \mathrm{~min}$ to 15.20 and $80.0 \mu \mathrm{M} \mathrm{C} 22: 6 \omega 3$ remained close to their respective control value, averaging respectively, $1.45 \pm 0.15$ and $4.10 \pm 0.30 \%$ ( $\mathrm{n}=2$ in both cases). The C22:6w3 content of phospholipids increased, however, to 12.8 and $23.3 \%$ in the cells exposed to 15.2 and $80.0 \mu \mathrm{M} \mathrm{C} 22: 6 \omega 3$. This corresponded to 2.10 and 3.82 times the paired control values (as compared to 1.71 and 2.61 times in Fig. 5).

In order to investigate possible competition between $\mathrm{C} 20: 5 \omega 3$ and $\mathrm{C} 22: 6 \omega 3$ in terms of their incorporation in cell phospholipids, the endothelial cells were incubated for $240 \mathrm{~min}$ in the presence of 16.6 $\mu \mathrm{M} \mathrm{C} 20: 5 \omega 3$ and/or 15.2 $\mu \mathrm{M} \mathrm{C} 20: 6 \omega 3$. As expected, in the cells exposed to only C20:5w3, the phospholipid content in $\mathrm{C} 20: 5 \omega 3$ and $\mathrm{C} 22: 5 \mathrm{\omega} 3$ was increased by 4.0 and $1.2 \%$, respectively, above the paired control value, whilst that of C22:6w3 was slightly decreased (Fig. 7). Likewise, in the cells exposed to only C22:6w3, the phospholipid content in this fatty acid was increased by $3.1 \%$ above control value, whilst that of $\mathrm{C} 20: 5 \omega 3$ and $\mathrm{C} 22: 5 \omega 3$ remained close to basal readings. Reciprocal competition between C20:5 133 and C22:6w3 was documented by the following 
findings. First, in the presence of $15.2 \mu \mathrm{M} \mathrm{C} 22: 6 \omega 3$, the incorporation of both $\mathrm{C} 20: 5 \omega 3$ and $\mathrm{C} 22: 5 \omega 3$ into the phospholipids of cells concomitantly exposed to $16.6 \mu \mathrm{M} \mathrm{C} 20: 5 \omega 3$ was decreased, after correction for basal value, by 10.0 and $44.0 \%$, respectively. Second, in the presence of $16.6 \mu \mathrm{M}$ $\mathrm{C} 20: 5 \omega 3$, the incorporation of $\mathrm{C} 22: 6 \omega 3$ into the phospholipids of cells simultaneously exposed to the latter fatty acid $(15.2 \mu \mathrm{M})$ was reduced, once again after correction for basal value, to $55 \%$ of the value otherwise recorded in the absence of C20:5 33 . These findings indicate that, at comparable concentrations of $\mathrm{C} 20: 5 \omega 3$ and $\mathrm{C} 22: 6 \omega 3$, their reciprocal primary competition for incorporation into phospholipids affects, in relative terms, more severely C22:6 $\omega 3$ than C20:5 23 .

When compared within the same experiments, the incorporation of albumin-bound C22:6w3 (15.2 $\mu \mathrm{M})$ into the phospholipids of BAEC was, after 120 or 240 min of incubation, slightly lower than that found in cells exposed to the same concentration of $\mathrm{C} 22: 6 \omega 3$ added to the medium as its mono-glyceride (Fig. 8). Thus, in the former case, the increments above the basal value for the phospholipid content in $\mathrm{C} 22: 6 \mathrm{w} 3$ (weight \%) as derived from duplicate determinations, averaged $71.1 \pm 2.8 \%(\mathrm{n}=2 ; \mathrm{P}<0.01)$ of that found at the same time of incubation in the latter case.

\section{Discussion}

The present study affords several pieces of information relevant to the use of the MCT:FO emulsion in the perspective of the enrichment of endothelial cell phospholipids in longchain polyunsaturated $\omega 3$ fatty acids.

First, such an enrichment was rapid, resulting for instance in a dramatic increase of the phospholipid content in C20:5 33 within 60 min (Fig. 1). Second, this enrichment was not rapidly reversible, persisting for at least $44 \mathrm{~h}$ after removal of MCT:FO from the culture medium (Fig. 2 and Table I). In this respect, the modest decrease in the C20:5 33 content of phospholipids during the final incubation period in the absence of MCT:FO could be attributable to its conversion to $\mathrm{C} 22: 5 \omega 3$. Indeed the content of the latter fatty acid in cell phospholipids strikingly increased during the final incubation. Third, the concentration dependency for such an enrichment indicated an optimal response in the presence of $0.5 \mathrm{mg} / \mathrm{ml} \mathrm{MCT:FO.} \mathrm{Fourth,} \mathrm{as} \mathrm{judged} \mathrm{from} \mathrm{the} \mathrm{ratio} \mathrm{between}$ the amount of $\mathrm{C} 20: 5 \mathrm{\omega} 3$ present in the phospholipids after 240 min of incubation in the presence of a lipid emulsion and the concentration of fish oil in the incubation medium, the MCT:FO emulsion and a 5:4:1 medium-chain triglyceride: long-chain triglyceride:fish oil emulsion were 2 to 5 times more efficient than respectively a 5:5 medium-chain triglyceride:fish oil emulsion and a pure fish oil emulsion. The increase in the triglyceride content of the endothelial cells above the basal value found in cells incubated in the absence of a lipid emulsion was significantly lower $(\mathrm{P}<0.01)$ in the cells exposed to MCT:FO as distinct from the 5:4:1 mediumchain triglyceride:long-chain triglyceride:fish oil emulsion. These comparisons indicate that, among the four tested emulsions, the most favourable results were obtained with MCT:FO. Finally, the incorporation of C20:5 23 and $\mathrm{C} 22: 6 \omega 3$ in the phospholipids of endothelial cells exposed to
MCT:FO (Fig. 3) was comparable to that achieved, over the same time of incubation, in cells exposed to albumin-bound $\mathrm{C} 20: 5 \omega 3$ or $\mathrm{C} 22: 6 \omega 3$, tested at the same concentration as that found for these two fatty acids in the MCT:FO emulsion (Fig. 5). At variance, however, with the results obtained in cells exposed to MCT:FO, the exposure of the endothelial cells to albumin-bound $\mathrm{C} 20: 5 \omega 3$ (or $\mathrm{C} 22: 6 \omega 3$ ) failed to increase

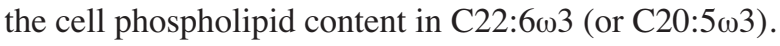

In the course of the present study, pilot experiments were also conducted to explore the possible protective effect of preincubation of HUVEC cells in the presence of MCT:FO against the $\mathrm{TNF} \alpha$-stimulated production of adhesion molecules. In these experiments, exposure of the HUVEC cells to $\mathrm{TNF} \alpha(10 \mathrm{ng} / \mathrm{ml})$ for $18 \mathrm{~h}$ caused an $\sim 12$-fold increase $(\mathrm{P}<0.001)$ in their E-selectin content from a basal value of $2.7 \pm 1.3 \mathrm{mg} / \mathrm{g}$ protein $(\mathrm{n}=9)$ to an experimental value of $33.9 \pm 5.4 \mathrm{mg} /$ protein $(\mathrm{n}=12)$. Likewise, within the same experiments, $\mathrm{TNF} \alpha$ caused a 3 -fold increase $(\mathrm{P}<0.01)$ of the HUVEC cell content in SVCAM-1 (soluble vascular cell adhesion molecule). Preincubation of the cells for $240 \mathrm{~min}$ with MCT:FO $(0.5 \mathrm{mg} / \mathrm{ml})$ prior to their exposure to $\mathrm{TNF} \alpha$ decreased their E-selectin and SVCAM-1 content to respectively $61.1 \pm 8.8(n=14 ; P<0.005)$ and $70.4 \pm 12.9 \%(n=7$; $\mathrm{P}<0.05$ ) of the mean corresponding values found within the same experiments in cells preincubated in the absence of MCT:FO prior to their exposure to TNF $\alpha(100.0 \pm 7.1 \% ; \mathrm{n}=12$ and $100.0 \pm 7.2 \% ; n=10)$.

The latter preliminary findings suggest that the MCT:FOinduced enrichment of cell phospholipids in long-chain polyunsaturated $\omega 3$ fatty acids may indeed protect endothelial cells against cytokine aggression. In the same perspective, it was recently observed that the bolus intravenous injection of MCT:FO affects $\mathrm{K}^{+}$and $\mathrm{Ca}^{2+}$ fluxes in aortic rings and protects their endothelial vasomotor function against oxidative stress $(5,6)$. Likewise, in $\omega 3$-depleted rats, the intravenous administration of MCT:FO emulsion $60 \mathrm{~min}$ before ex-vivo characterization of heart function during post-ischemic reperfusion was found to improve cardiac function, as judged from the product of the left ventricular developed pressure by the heart rate (7). In conclusion, these findings support the proposal of a beneficial effect of MCT:FO on cardiovascular function.

\section{Acknowledgements}

This study was supported by a grant from the Région de Bruxelles-Capitale (BC-BR 246/2410, Brussels, Belgium) to Target Hit s.a. (Brussels, Belgium). The lipid emulsions were provided by B. Braun Melsungen (Melsungen, Germany). We are grateful to C. Demesmaeker for the secretarial help.

\section{References}

1. Portois L, Deckelbaum RJ, Malaisse WJ and Carpentier YA: Accumulation rapide d'eicosapentaenoate dans les phospholipides cellulaires après injection intraveineuse d'une émulsion d'huile de poisson et de triglycérides à chaîne moyenne à des sujets normaux. Nutr Clin Metab 18 (suppl 1): 53, 2004.

2. Scruel O, Dupont IE and Carpentier YA: Adding medium chain triglycerides to fish oil in lipid emulsion particles improves n-3 fatty acid targeting to endothelial cell phospholipids. Clin Nutr 21 (suppl 1): 52, 2002. 
3. Portois L, Malaisse WJ and Carpentier YA: Rapid and sustained incorporation of $\omega 3$-fatty acids in the phospholipids of endothelial cells exposed to a novel medium-chain triglyceride:fish oil emulsion. Clin Nutr 24: 566, 2005.

4. Simoens C, Richelle M, Rössle C, Derluyn M, Deckelaum RJ and Carpentier YA: Manipulation of tissue fatty acid profile by intravenous lipids in dogs. Clin Nutr 14: 177-185, 1995.

5. Courtois P, Louchami K, Portois L, Chardigny J-M, Sener A, Carpentier YA and Malaisse WJ: Effects of a medium-chain triglyceride:fish oil emulsion administered intravenously to $\omega 3$ fatty acid-depleted rats on cationic fluxes in aortic rings. Int J Mol Med 16: 1089-1093, 2005.
6. Fontaine D, Otto A, Portois L, Berkenbaum G, Fontaine J, Malaisse WJ and Carpentier YA: Protection of aortic endothelial function by injection of a medium-chain triglyceride/fish oil emulsion in streptozotocin-induced diabetic rats. JPEN J Parenter Enteral Nutr 29: S26, 2005.

7. Peltier S, Malaisse WJ, Portois L, Novel-Chaté V, Chardigny J-M, Carpentier YA and Leverve XM: L'administration in vivo d'une émulsion lipidique enrichie en huile de poisson améliore la fonction cardiaque post-ischémique de rats carencés en acides gras polyinsaturés n-3. Nutr Clin Metab 19 (suppl 1): P1, 2005. 